\title{
Oral glutamate intake reduces acute and chronic effects of ethanol in rodents
}

\author{
Araya Supawat, Supawadee Srisuwan and Jintana Sattayasai* \\ Department of Pharmacology, Faculty of Medicine, Khon Kaen University, Khon Kaen, Thailand
}

*For correspondence: Email: sjinta@kku.ac.th; Tel/Fax: 66-43-348397

Received: 18 February 2016

Revised accepted: 12 June 2016

\begin{abstract}
Purpose: To assess the effects of oral glutamate intake on acute motor effects and chronic intake of ethanol in rodents.

Methods: The acute effects of ethanol on motor function were studied in ICR mice by giving 2 or $6 \mathrm{~g} / \mathrm{kg}$ of ethanol $2 \mathrm{~h}$ after distilled water or $2.5 \mathrm{~g} / \mathrm{kg}$ glutamate per os. Thirty minutes after ethanol treatment, behavioral assays, including rotarod tests and foot print analysis were monitored. In chronic ethanol treatment, male Wistar rats were trained to consume ethanol-sucrose solution during a 2-h period daily, starting with $2 \%$ ethanol/10 \% sucrose and gradually increasing to $10 \%$ ethanol/5\% sucrose solution over 56 days. After training session, the drug treatment phase was done for 10 days. The animals were force-fed $50 \mathrm{mg} / \mathrm{kg} /$ day topiramate or $2.5 \mathrm{~g} / \mathrm{kg} /$ day glutamate $2 \mathrm{~h}$ before ethanol treatment sessions. Each day, ethanol intake, water intake, food intake and body weight were recorded.

Results: Mice that received 2 or $6 \mathrm{~g} / \mathrm{kg}$ of ethanol orally, showed a significant reduction in time on the rod in the rotarod test and a significant increase in both forelimb and hindlimb stride lengths when compared to control. Oral treatment with $2.5 \mathrm{~g} / \mathrm{kg}$ of glutamate reversed the acute motor effects of ethanol. In chronic ethanol treatment, the intake of $10 \%$ ethanol/5 \% sucrose, accessible for $2 h$, was significantly decreased in rats treated with either topiramate or glutamate.

Conclusion: These results provide evidence that oral glutamate administration help to reduce the acute motor effects of ethanol in mice and ethanol intake in the chronic ethanol drinking rats.
\end{abstract}

Keywords: Ethanol, Glutamate, Motor functions, Ethanol intake, Rodents

Tropical Journal of Pharmaceutical Research is indexed by Science Citation Index (SciSearch), Scopus, International Pharmaceutical Abstract, Chemical Abstracts, Embase, Index Copernicus, EBSCO, African Index Medicus, JournalSeek, Journal Citation Reports/Science Edition, Directory of Open Access Journals (DOAJ), African Journal Online, Bioline International, Open-J-Gate and Pharmacy Abstracts

\section{INTRODUCTION}

Glutamate, the principal excitatory amino acid neurotransmitter present in the mammalian brain, is one of the neurotransmitters responsible for neuronal effects of ethanol in both acute and chronic alcohol consumption. In acute alcohol consumption, all glutamate receptors, including $\mathrm{N}$-methyl-D-aspartate (NMDA) and L-alphaamino-3-hydroxy-5-methyl-isoxazole-4-propionic acid ionotropic (AMPA) receptors are inhibited [1]. Together with increased inhibitory neurotransmission through gamma-aminobutyric acid (GABA), acute alcohol exposure leads to a sedated state and impaired motor coordination in drinkers $[1,2]$. On the other hand, chronic use of alcohol seems to upregulate NMDA receptor expression in the brain and leads to alcohol dependence and relapse-like alcohol drinking $[1,2]$. Glutamate also plays an important role in the reward system of alcohol addiction [3,4,5]. Increased extracellular glutamate levels were observed in the reward system during ethanol withdrawal [6]. Currently, several studies have focused on the investigation of glutamatergic agents in maintaining glutamate homeostasis, 
modifying alcohol's effects, and reducing alcohol intake $[7,8]$. Acamprosate, one of the approved treatments for alcoholism, is proposed to exert at least part of its effsct by altering glutamatergic function $[9,10]$. Topiramate, an anticonvulsant, that inhibits glutamate release and blocks AMPA/kainate receptors, can also be used in the treatment of alcohol dependence [11].

Glutamate is found in abundant amounts in many natural and prepared foods as a food flavoring agent for the umami taste. Recently, it was shown that monosodium glutamate at 2.5 or 4 $\mathrm{g} / \mathrm{kg}$ per os could markedly elevate the glutamate level in the brain and other organs in mice and reached peak values at $90-120 \mathrm{~min}$ [12]. Thus, when drinking alcohol with food as a source of glutamate, interactions between ethanol and glutamate might occur. This study was aimed to investigate the effects of oral administration of glutamate on the acute effects of ethanol on motor functions and alcohol intake in alcohol addiction.

\section{EXPERIMENTAL}

\section{Experimental animals}

In this study, male outbred Mlac:ICR mice, 6-8 wks old, weighing 25-35 g, and male outbred Wistar rats, 6-8 wks old, weighing $250-350 \mathrm{~g}$, were purchased from the National Laboratory Animal Center, Mahidol University, Thailand. The animals had free access to a commercial diet (CP, Thailand) and water, and were housed in a room with a 12-h light: 12-h dark cycle under controlled temperature and humidity. All animal experiments were strictly in accordance with international ethical guidelines [13] and Ethics of Animal Experimentation of National Research Council of Thailand concerning the Care and Use of Laboratory Animals. The experimental protocols also received the approval of Animal Ethics Committee of Khon Kaen University (approval no. 0514.1.12.2/78).

\section{Chemicals and reagents}

Ethanol (BDH Prolabo Chemicals, EC), sucrose (Ajax Fine Chem Pty Ltd, New Zealand), topiramate (Topamax $\AA$, Janssen Pharmaceuticals, Inc. Toronto, Canada) and Lglutamic acid (Sigma-Aldrich, USA) were used in this study. The chemicals were dissolved in distilled water on the day of the experiment and given to the animals in a dose of $0.05 \mathrm{ml} / 10 \mathrm{~g}$ body weight. Doses of ethanol used were expressed as $\mathrm{g} / \mathrm{kg}$.

\section{Acute ethanol treatment}

Each of the mice were force fed two times $2 \mathrm{~h}$ apart. First, distilled water or $2.5 \mathrm{~g} / \mathrm{kg}$ glutamate [12] was administered followed by distilled water or ethanol (2 or $6 \mathrm{~g} / \mathrm{kg}$ ) [14]. Thirty minutes after the second treatment, the rotarod tests and foot print analyses were performed.

\section{Rotarod test}

The rotarod test was done to assess motor coordination and balance in mice. The AccuRotor Rotarod (Accuscan Instruments, Columbus, $\mathrm{OH}$ ) was used for fixed-speed rota-rod (FSRR) tests. Mice were placed with the forepaws on bars (diameter $2.5 \mathrm{~cm}$ ) which were turning at $12 \mathrm{rpm}$ and the time that the animal remained on the rod was recorded [14]. The maximum observed time was set at $60 \mathrm{~s}$.

\section{Foot print analysis}

Foot print analysis was used to assess ataxia and gait abnormalities in mice as described earlier [15]. Animals were made to walk along a $60 \mathrm{~cm}$ long, $7 \mathrm{~cm}$ wide runner with $10 \mathrm{~cm}$ walls by lighting a lamp at the start and placing a dark box at the end. The runner was lined with white paper, and the fore and hind paws of the animals were dipped in red and blue nontoxic colors to record the footprints. Six middle steps of a series of steps were analyzed and the distances between two forelimb and two hindlimb pawprints were measured as forelimb stride length (FSL) and hindlimb stride length (HSL), respectively.

\section{Assessment of chronic ethanol consumption in rats}

In this chronic study, male Wistar rats were treated as described earlier [16] and topiramate, an antiepileptic agent that reduces ethanol consumption [11] was used as a positive control. Animals were individually housed and received ad libitum access to standard rodent chow and water. The experiments were performed during the light cycle. In the training phase, rats were given free access to ethanol in sucrose solutions during two-hour sessions at 10:00-12:00 am of each day for 56 days. Ethanol-sucrose solutions were presented in $25 \mathrm{~mL}$ graduated plastic tubes with rubber stoppers and metal sipper tubes were inserted through the cage. The concentration of ethanol in these solutions was systematically increased, while the concentration of sucrose was decreased over a 56-day period. The ethanol-sucrose solution given to the animals were $2 \%$ ethanol $/ 10 \%$ sucrose solution on days $1-11,5 \%$ ethanol- $5 \%$ sucrose solution 
on days 12 - 24, $8 \%$ ethanol/5\% sucrose solution on days 25 - 38 and $10 \%$ ethanol/5\% sucrose solution on days 39 - 56 which continued for another 10 days for the treatment phase. The 10th day drug treatment phase began after animals had completed 8 weeks (56 days) of training on drinking. Animals were randomly assigned to control (distilled water), topiramate at $50 \mathrm{mg} / \mathrm{kg} /$ day and glutamate at $2.5 \mathrm{~g} / \mathrm{kg} / \mathrm{day}$ treatment groups with 6 animals in each group. On each day of the drug treatment phase, $2 \mathrm{~h}$ before the ethanol session, animals received intragastrically distilled water, $50 \mathrm{mg} / \mathrm{kg}$ topiramate or $2.5 \mathrm{~g} / \mathrm{kg}$ glutamate, once daily. After that, a 2-h session of free access to a $10 \%$ ethanol-5 \% sucrose solution was initiated. On each day, the amount of ethanol intake $(\mathrm{g} / \mathrm{kg})$ in the two-hour session, water intake (ml/day) and food intake (g/day) were recorded. Animal body weights were recorded daily during the whole experiment to monitor drug-induced body weight changes.

\section{Statistical analysis}

The data are presented as means \pm standard error of means (SEM). For the acute effects of ethanol on motor functions, one-way analysis of variance (ANOVA) followed by Tukey post-hoc test) and Student t-tests were used. Results were considered significant at $p<0.05$. In the assessment of chronic ethanol consumption in rats, two-way ANOVA with groups and times as factors, were performed.

\section{RESULTS}

\section{Effect of glutamate on acute ethanol treatment}

In the rotarod test, the control animals on wateronly showed normal coordination and could stay on the rod for over $60 \mathrm{sec}$. Ethanol, at either 2 or $6 \mathrm{~g} / \mathrm{kg}$, significantly $(p<0.001)$ decreased the time on rod when compared to the control (Figure 1). Mice that received $2.5 \mathrm{~g} / \mathrm{kg}$ glutamate had normal coordination and could stay on rod for over $60 \mathrm{sec}$. Time on rods of mice that received glutamate with either 2 or $6 \mathrm{~g} / \mathrm{kg}$ of ethanol were comparable to the control which suggested that glutamate could completely reverse the effects of ethanol.

Foot print analysis showed that the control animals used only the front parts of the paws to walk on and a narrow-based stance with close proximity forelimb and hindlimb footprints with $5.71 \pm 0.48$ and $5.30 \pm 0.49 \mathrm{~cm}$ of forelimb and hindlimb stride lengths. The stepping patterns of animals that received either doses of ethanol were different from the control animals. Animals treated with ethanol, at either 2 or $6 \mathrm{~g} / \mathrm{kg}$, walked on their whole paw with a significant increase in FSL $(p=0.037,0.043)$ and HSL $(p=0.010$, $0.050)$ when compared to the control (Figure 2). Mice that received $2.5 \mathrm{~g} / \mathrm{kg}$ glutamate could reverse the effects of $2 \mathrm{~g} / \mathrm{kg}$, but not $6 \mathrm{~g} / \mathrm{kg}$, of ethanol on FSL and HSL to the control length.

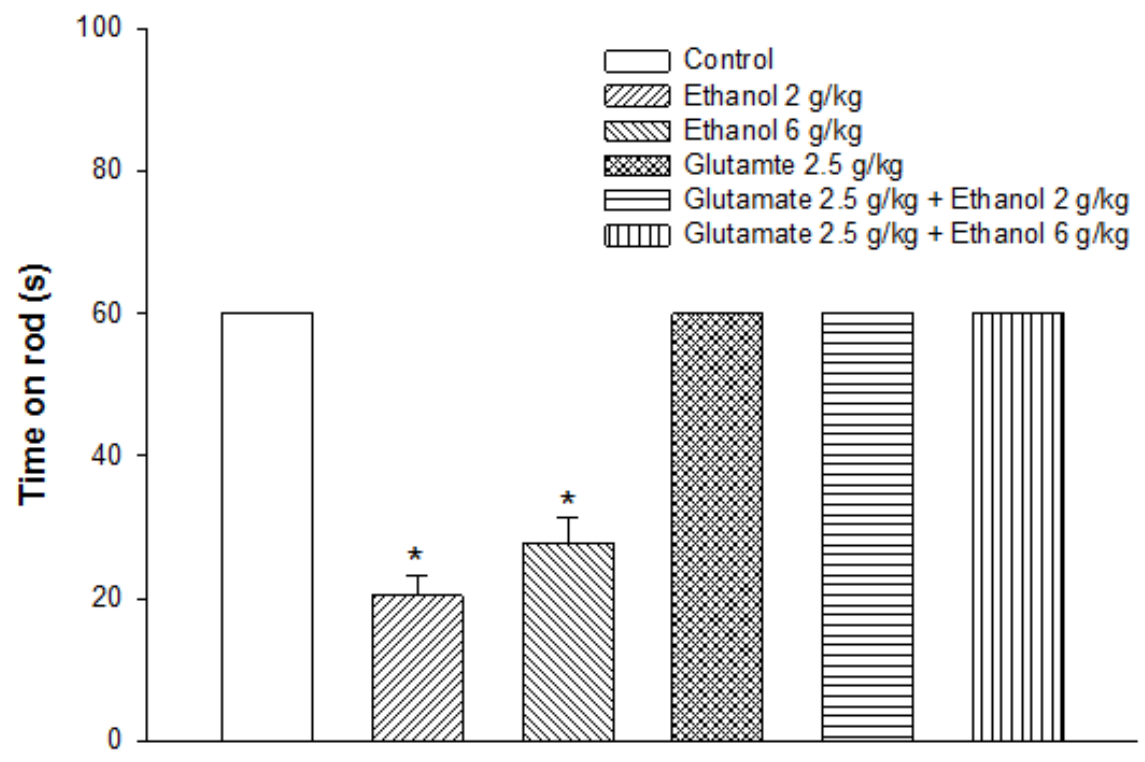

Figure 1: Effect of glutamate on ethanol-induced changes in coordination in the rotarod test. Ethanol, at either 2 or $6 \mathrm{~g} / \mathrm{kg}$, significantly $(p<0.001)$ reduced the time on the bar. Glutamate $(2.5 \mathrm{~g} / \mathrm{kg})$ reversed the effects of ethanol on coordination. Significant differences, when compared to the control, are denoted by * 


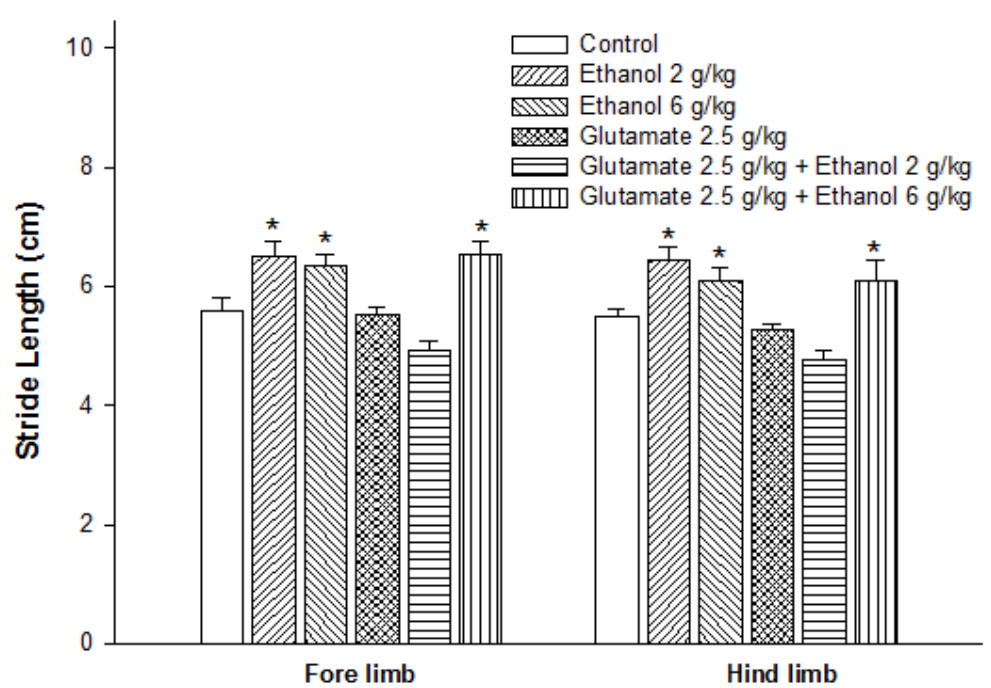

Figure 2: Effects of glutamate on ethanol-induced changes in FSL and HSL. Ethanol 2 or $6 \mathrm{~g} / \mathrm{kg}$ could significantly increase both FSL and HSL. Glutamate $(2.5 \mathrm{~g} / \mathrm{kg})$ reversed the effects of $2 \mathrm{~g} / \mathrm{kg}$ ethanol on FSL and HSL to normal levels. *Significantly different, compared to the control

Table 1: Effect of glutamate and topiramate on ethanol intake in rats

\begin{tabular}{|c|c|c|c|c|c|}
\hline \multirow[b]{2}{*}{ Day } & \multirow{2}{*}{$\begin{array}{c}\text { Control } \\
\text { Ethanol Intake } \\
(g / k g / 2 ~ h) \\
\text { (mean } \pm \text { SEM) }\end{array}$} & \multicolumn{2}{|c|}{ TPM (50mg/kg/day) } & \multicolumn{2}{|c|}{ Glutamate (2.5g/kg/day) } \\
\hline & & $\begin{array}{c}\text { Ethanol Intake } \\
(\mathrm{g} / \mathrm{kg} / 2 \mathrm{~h}) \\
(\text { mean } \pm \text { SEM) }\end{array}$ & P-value & $\begin{array}{c}\text { Ethanol } \\
\text { Intake }(\mathrm{g} / \mathrm{kg} / \\
2 \mathrm{~h}) \\
(\text { mean }+ \text { SEM) }\end{array}$ & P-value \\
\hline 1 & $1.411 \pm 0.048$ & $1.066 \pm 0.078^{*}$ & 0.004 & $1.344 \pm 0.106$ & 1.000 \\
\hline 2 & $1.819 \pm 0.110$ & $1.290 \pm 0.104^{*}$ & 0.026 & $1.331 \pm 0.102^{*}$ & 0.044 \\
\hline 3 & $1.607 \pm 0.159$ & $1.103 \pm 0.133^{*}$ & 0.035 & $1.382+0.175$ & 0.146 \\
\hline 4 & $1.719 \pm 0.163$ & $1.042 \pm 0.0659^{*}$ & 0.018 & $1.252 \pm 0.128^{*}$ & 0.048 \\
\hline 5 & $1.604 \mp 0.133$ & $0.781 \mp 0.0613^{*}$ & 0.002 & $1.008 \mp 0.107^{*}$ & 0.028 \\
\hline 6 & $1.604+0.178$ & $0.910+0.107^{*}$ & 0.012 & $1.025 \pm 0.131^{*}$ & 0.042 \\
\hline 7 & $1.584+0.137$ & $0.939+0.133^{*}$ & 0.016 & $1.028+0.113^{*}$ & 0.041 \\
\hline 8 & $1.786+0.180$ & $0.858+0.109^{*}$ & 0.003 & $1.376+0.167$ & 0.126 \\
\hline 9 & $1.768+0.292$ & $0.680 \mp 0.120^{*}$ & 0.008 & $1.010+0.113^{*}$ & 0.036 \\
\hline 10 & $1.699+0.190$ & $0.867 \mp 0.122^{*}$ & 0.002 & $0.973 \mp 0.112^{*}$ & 0.007 \\
\hline
\end{tabular}

All values are expressed as mean \pm SEM. Significant differences are denoted by * when compared to the control group of the same day

\section{Effect of glutamate on chronic ethanol consumption}

At the end of the training phase, the mean daily intake of ethanol in $\mathrm{g} / \mathrm{kg}$ for each treatment group for the baseline phase, was of $1.529 \mathrm{~g} / \mathrm{kg} / 2-\mathrm{h}$ session ( \pm 0.088 SEM). During the 10 days of the treatment phase, the control animals showed no change in the amount of ethanol intake. A significant reduction of ethanol intake that was seen in topiramate-treated group, when compared to the control, can be seen from day 1 to day 10 (Table 1). Glutamate treatment, at 2.5 $\mathrm{mg} / \mathrm{kg} /$ day, also significantly reduced the amount of ethanol intake from day 2 to day 10 and the effects were comparable to topiramate at 50 $\mathrm{mg} / \mathrm{kg} /$ day. A two-way repeated measures ANOVA showed a significant effect of treatment $[F(3,239)=16.618, p<0.001]$, without any significance in treatment $x$ day interactions $(p=$ 0.869).

Significant reduction of ethanol intake $(\mathrm{g} / \mathrm{kg} / \mathrm{two}-$ hour session) can be seen in rats treated with topiramate $(50 \mathrm{mg} / \mathrm{kg} /$ day $)$ or glutamate $(2.5$ $\mathrm{g} / \mathrm{kg} /$ day) from day 1 or day 2 of the treatment phase and was still prominent at the end of the experiment.

No significant differences of the mean volume of water, food intake or change of body weight could be seen in all treatment groups when compared to the control (data not shown).

\section{DISCUSSION}

Recently, it has been shown that monosodium glutamate (MSG), the primary component of 
umami taste, can be used as a substitute to initiate ethanol drinking in both C57BL/6J and DBA/2J mice [17]. Interestingly, this study is the first to show that intragastric administration of glutamate could reduce both the acute effects of ethanol on motor functions and chronic ethanol intake.

Generally, ethanol modulates synaptic efficacy in many brain areas, including the cerebellum and cortical regions $[18,19]$ and causes motor impairment from the inhibition of ionotropic glutamate receptors and enhancing the inhibitory action of GABA $[20,21]$. It is noted that glutamate could be detected in the brain with peak concentrations at approximately $2 \mathrm{~h}$ after oral administration of $2.5 \mathrm{~g} / \mathrm{kg}$ glutamate [17]. In the present study, oral administration of glutamate, 2 $h$ before ethanol, might have increased the glutamate levels in the brain, activated glutamate receptors and helped reduce the acute effects of ethanol on motor functions.

In the chronic ethanol consumption model, topiramate treatment clearly reduced the ethanol intake of the rats. It has been shown previously that topiramate, by facilitation of inhibitory GABA effects and antagonism of AMPA/kainate glutamate receptors can decrease ethanol reinforcement and the propensity to drink [22,23]. Recently, glutamate was able to induce more ethanol drinking in C57BL6/J and DBA/2J mice and the authors suggested that the umami effect of glutamate is responsible for the effect [17]. In the present experiment, glutamate administered by an intragastric tube, bypassed the umami taste, reduced ethanol intake in rats with a history of chronic alcohol consumption. It is interesting to note that changes in the balance between synaptic and extrasynaptic glutamate levels in the brain in turn influence signaling through pre- and post-synaptic glutamate receptors, and thus affect synaptic plasticity and circuit-level activity [24].

In chronic exposure to cocaine, a decrease in extrasynaptic glutamate concentrations in the nucleus accumben (NAc) and a decreased tone of presynaptic inhibitory mGluR2/3 glutamate receptors was observed [24]. MGluR2/3 glutamate receptors are inhibitory to glutamatergic neurotransmission; the decreased tone of these receptors leads in turn to enhanced glutamate release in the prefrontal cortex-NAc projection and activates drug-seeking behavior [25]. Giving glutamate orally might increase extrasynaptic glutamate level in the brain $[17,26]$ and reduce ethanol-seeking behavior.
The results from this study suggest that, glutamate, as one of the common ingredients found in all kinds of foods, might exert a very interesting interaction with ethanol in either its acute or chronic effects.

\section{CONCLUSION}

These results provide evidence that oral glutamate administration reduces acute motor effects of ethanol and ethanol intake in the chronic ethanol drinking rat model.

\section{DECLARATIONS}

\section{Acknowledgement}

This study was supported by the invitation research grant of Faculty of Medicine, Khon Kaen University, Thailand (Grant no. 156221). Araya Supawat was partly supported by a grant from Postgraduate Study Support Grant, Faculty of Medicine, Khon Kaen University. The authors would like to acknowledge Professor James A Will for editing the manuscript via Publication Clinic KKU, Thailand.

\section{Conflict of Interest}

No conflict of interest associated with this work.

\section{Contribution of Authors}

The authors declare that this work was done by the authors named in this article and all liabilities pertaining to claims relating to the content of this article will be borne by them.

\section{REFERENCES}

1. Most D, Ferguson L, Harris A. Molecular basis of alcoholism. Handb Clin Neurol 2014; 125: 89-111.

2. Field M, Wiers RW, Christiansen P, Fillmore MT, Verster JC. Acute alcohol effects on inhibitory control and implicit cognition: implications for loss of control over drinking. Alcohol Clin Exp Res 2010; 34: 1346-1352.

3. Gass JT, Olive MF. Glutamatergic substrates of drug addiction and alcoholism. Biochem Pharmacol 2008; 75: 218-265.

4. Kapasova Z, Szumlinski KK. Strain differences in alcoholinduced neurochemical plasticity: a role for accumbens glutamate in alcohol intake. Alcohol Clin Exp Res 2008; 32: 617-631.

5. Ding ZM, Engleman EA, Rodd ZA, McBride WJ. Ethanol increases glutamate neurotransmission in the posterior ventral tegmental area of female wistar rats. Alcohol Clin Exp Res 2012; 36: 633-640. 
6. Dahchour A, Hoffman A, Deitrich R, de Witte P. Effects of ethanol on extracellular amino acid levels in high-and low-alcohol sensitive rats: a microdialysis study. Alcohol 2000; 35: 548-553.

7. Vengeliene V, Bachteler D, Danysz W, Spanagel R. The role of the NMDA receptor in alcohol relapse: a pharmacological mapping study using the alcohol deprivation effect. Neuropharmacology 2005; 48: 822829.

8. Scofield MD, Kalivas PW. Astrocytic dysfunction and addiction: consequences of impaired glutamate homeostasis. Neuroscientist 2014; 20: 610-622.

9. Kiefer F, Mann K. Acamprosate: how, where, and for whom does it work? Mechanism of action, treatment targets, and individualized therapy. Curr Pharm Des 2010; 16: 2098-2102.

10. Holmes A, Spanagel R, Krystal JH. Glutamatergic targets for new alcohol medications. Psychopharmacology (Berl) 2013; 229: 539-554.

11. De Sousa A. The role of topiramate and other anticonvulsants in the treatment of alcohol dependence: a clinical review. CNS Neurol Disord Drug Targets 2010; 9: 45-49.

12. Yu T, Zhao Y, Shi W, Ma R, Yu L. Effects of maternal oral administration of monosodium glutamate at a late stage of pregnancy on developing mouse fetal brain. Brain Res 1997; 747: 195-206.

13. Garber JC, Barbee RW, bielitzki JT, Clayton LA, Donovan JC, et al. The guide for the care and use of laboratory animals, 8th ed. Institute for Laboratory Animal Research. The National Academic Press, Washington DC, USA 2011.

14. Soares PM, Patrocinio MC, Assreuy AM, Siqueira RC, Lima NM, et al. Aminophylline (a theophyllineethylenediamine complex) blocks ethanol behavioral effects in mice. Behav Pharmacol 2009; 20: 297-302.

15. Karadayian AG, Cutrera RA. Alcohol hangover: type and time-extension of motor function impairments. Behav Brain Res 2013; 247: 165-173.
16. Knapp CM, Mercado M, Markley TL, Crosby S, Ciraulo $D A$, et al. Zonisamide decreases ethanol intake in rats and mice. Pharmacol Biochem Behav 2007; 87: 65-72.

17. McCool BA, Chappell AM. Persistent enhancement of ethanol drinking following a monosodium glutamatesubstitution procedure in C57BL6/J and DBA/2J mice. Alcohol 2014; 48: 55-61.

18. Hirono M, Yamada M, Obata K. Ethanol enhances both action potential-dependent and action potentialindependent GABAergic transmission onto cerebellar Purkinje cells. Neuropharmacology 2009; 57: 109-120.

19. Tiwari $V$, Veeraiah $P$, Subramaniam $V$, Patel $A B$. Differential effects of ethanol on regional glutamatergic and GABAergic neurotransmitter pathways in mouse brain. J Neurochem 2014; 128: 628-640.

20. Matchett JA, Erickson CK. Alteration of ethanol-induced changes in locomotor activity by adrenergic blockers in mice. Psychopharmacology (Berl) 1977; 52: 201-206.

21. Wakita $M$, Shin MC, Iwata S, Nonaka K, Akaike N. Effects of ethanol on GABA(A) receptors in GABAergic and glutamatergic presynaptic nerve terminals. J Pharmacol Exp Ther 2012; 341: 809-819.

22. Johnson BA. Recent advances in the development of treatments for alcohol and cocaine dependence: focus on topiramate and other modulators of GABA or glutamate function. CNS Drugs 2005; 19: 873-896.

23. Johnson BA, Ait-Daoud N. Topiramate in the new generation of drugs: efficacy in the treatment of alcoholic patients. Curr Pharm Des 2010; 16: 21032112.

24. Reissner KJ, Kalivas PW. Using glutamate homeostasis as a target for treating addictive disorders. Behav Pharmacol 2010; 21: 514-522.

25. Kalivas PW. The glutamate homeostasis hypothesis of addiction. Nat Rev Neurosci 2009; 10: 561-572.

26. Monno A, Vezzani A, Bastone A, Salmona M, Garattini S. Extracellular glutamate levels in the hypothalamus and hippocampus of rats after acute or chronic oral intake of monosodium glutamate. Neurosci Lett 1995; 193: 45-48. 